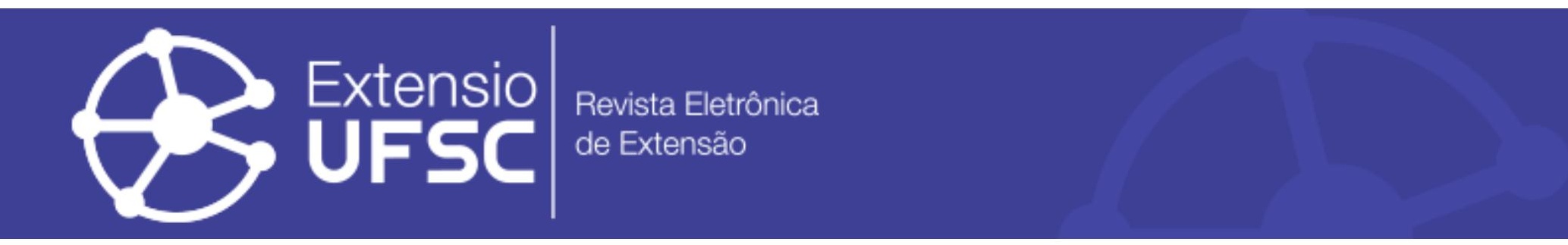

\title{
JOVENS TUTORES DE PROGRAMAÇÃO: UM RELATO DE EXPERIÊNCIA
}

\author{
Jean Carlo R. Hauck \\ Universidade Federal de Santa Catarina \\ jean.hauck@ufsc.br \\ Christiane Gresse von Wangenheim \\ Universidade Federal de Santa Catarina \\ gresse@gmail.com \\ Giselle Medeiros \\ Prefeitura Municipal de Florianópolis \\ giselle.medeiros@prof.pmf.sc.gov.br
}

\author{
Raul Missfeldt Filho \\ Universidade Federal de Santa Catarina \\ raul_mf96@hotmail.com \\ Nathalia Alves \\ Universidade Federal de Santa Catarina \\ nathaliacruzalves@gmail.com \\ Silvia Laurentino \\ Universidade Federal de Santa Catarina \\ silvia.laurentino@outlook.com \\ Vinícius Santos \\ Involves Tecnologia \\ vinicius.santos@involves.com.br
}

\begin{abstract}
Resumo
O projeto Jovens Tutores de Programação tem o objetivo de capacitar jovens dos últimos anos do ensino fundamental para a aplicação e ensino de programação de aplicativos móveis, com o apoio de profissionais da indústria de software e de alunos extensionistas, ao mesmo tempo que ensina o conhecimento computacional e programação a outros alunos de uma escola pública municipal de Florianópolis. O projeto foi realizado de abril a setembro de 2017. Durante o projeto foram realizadas as etapas de: preparação de unidades instrucionais e ferramentas, capacitação dos participantes, formação para os tutores, realização de oficinas de programação e documentação do projeto. Os resultados observados indicaram a obtenção dos objetivos do projeto, e incluem: capacitação de três jovens tutores de programação e seis profissionais da indústria, realização de oficinas de programação para cinquenta alunos da escola, diversos prêmios e destaques em feiras e eventos.

Palavras-chave: Ensino de Computação. Pensamento Computacional. Peer Tutoring.
\end{abstract}

\section{YOUNG PROGRAMMING TUTORS: AN EXPERIENCE REPORT}

\begin{abstract}
The Young Tutors of Programming project has the objective of training youngsters from the last years of elementary education for the application and teaching of mobile application programming, with the support of professionals from the software industry and extension students, while teaching the knowledge and programming to other students of a municipal public school in Florianópolis. The project was carried out from April to September 2017. During the project the following stages were carried out: preparation of instructional units and tools, training for participants and tutors, programming workshops and project documentation. The results show the achievement of the project objectives and include: training of three young tutors and six software professionals, programming workshops for fifty students at the school, various awards and highlights at fairs and events.
\end{abstract}

Keywords: Programming Teaching, Computational Thinking, Peer Tutoring.

\section{JÓVENES TUTORES DE PROGRAMACIÓN: UN RELATO DE EXPERIENCIA}

\section{Resumen}

El proyecto Jóvenes Tutores de Programación tiene el objetivo de capacitar jóvenes de los últimos años de la enseñanza fundamental para la aplicación y enseñanza de programación de aplicaciones móviles, con el apoyo de profesionales de la industria de software y de alumnos extensionistas, al mismo tiempo que enseña el conocimiento computacional y programación a otros alumnos de una escuela pública municipal de Florianópolis. El proyecto se realizó de abril a septiembre de 2017. Durante el proyecto se realizaron las etapas de: preparación de unidades instruccionales y herramientas, capacitación de los participantes, formación para los tutores, realización de talleres de programación y documentación del proyecto. Los resultados observados indicaron el logro de los objetivos del proyecto, e incluyen: capacitación de tres jóvenes tutores de programación y seis profesionales de la industria de software, realización de talleres de programación para cincuenta alumnos de la escuela, diversos premios y destaques en ferias y eventos.

Palavras clave: Enseñanza de Computación. Pensamiento Computacional. Peer Tutoring. 
Jovens tutores de programação: um relato de experiência

\section{INTRODUÇÃO}

Atualmente tem sido observada uma tendência de se ensinar computação já desde os primeiros anos escolares, como forma de auxiliar no desenvolvimento nos alunos das competências necessárias para o século XXI (CSTA, 2017). O conhecimento dos princípios da computação e o desenvolvimento do pensamento computacional (WILSON et al., 2010), abrem a possibilidade de que todas as pessoas possam ser criadoras e não apenas consumidoras de conteúdo digital, além de poderem compreender melhor como as coisas são efetivamente desenvolvidas nos computadores, celulares e afins (NATIONAL RESEARCH COUNCIL, 2011).

O ensino de computação, e particularmente o ensino de programação, tem sido levado aos alunos do ensino fundamental de diversas formas: por meio de disciplinas específicas, oficinas de contraturno escolar, clubes de programação e de forma multidisciplinar integrada ao currículo (LYE \& KOH, 2014). Nesse sentido, diversas iniciativas têm sido criadas para incentivar o ensino de computação para crianças, tais como: Code.org (Code.ORG, 2018), Technovation (TECHNOVATION, 2018) e "Computação na Escola" (INCOD/INE/UFSC, 2018), entre outras. A iniciativa "Computação na Escola" coordenada pelo Instituto Nacional para Convergência Digital do Departamento de Informática e Estatística - Centro Tecnológico da Universidade Federal de Santa Catarina (INCOD/INE/UFSC, 2018) tem o objetivo de expandir o aprendizado de computação no Ensino Fundamental e Médio. Buscando ampliar o ensino de computação no cenário de recursos limitados, especialmente das escolas públicas, a iniciativa "Computação na Escola" tem realizado pesquisa, desenvolvimento, aplicação e avaliação de unidades instrucionais.

Visando a sustentabilidade do ensino de computação nas escolas brasileiras e levando em consideração a falta de professores da educação básica com a formação necessária, a iniciativa “Computação na Escola” criou o projeto "Jovens Tutores de Programação", que objetiva formar alunos do ensino fundamental para o pensamento computacional e programação de aplicativos móveis. Assim, o projeto Jovens Tutores de Programação envolve jovens do ensino fundamental como tutores de programação, tendo com mentores, profissionais de desenvolvimento de software e alunos extensionistas universitários, na aplicação de oficinas de programação de aplicativos móveis para crianças do ensino fundamental de escolas públicas.

A escolha pelo ensino de programação de aplicativos móveis se justifica pela ampla difusão do uso de celulares, sendo que no Brasil, $77,1 \%$ da população com mais de 10 anos 
Jovens tutores de programação: um relato de experiência

possui telefone móvel celular para uso pessoal (IBGE, 2016). Celulares são, atualmente, a forma mais utilizada para acesso à internet, sendo utilizados para esse fim por $94,6 \%$ dos brasileiros que possuem acesso à internet (IBGE, 2016).

O presente artigo é dividido da seguinte forma: na seção de materiais e métodos, as atividades realizadas e os atores envolvidos são apresentados, na seção seguinte os resultados do projeto são discutidos, e na última seção as considerações finais são apresentadas.

\section{MATERIAIS E MÉTODOS}

A extensão universitária tem papel fundamental na formação dos alunos do ensino superior, pois tem o potencial de levar alunos de cursos como Ciências da Computação (CCO) ou Sistemas de Informação (SIN), por exemplo, a experienciar no mundo real conteúdos curriculares muitas vezes não suficientemente aplicados na prática em sala de aula (SCAICO et al, 2012; CASTRO, 2004).

Nesse sentido, o projeto Jovens Tutores de Programação tem como objetivo principal capacitar jovens dos últimos anos do ensino fundamental para a aplicação e ensino de programação de aplicativos móveis, envolvendo profissionais da indústria de software e alunos extensionistas, ao mesmo tempo que se ensina o conhecimento computacional e programação para outras crianças em uma escola pública municipal de Florianópolis.

Conforme apresenta o Quadro 1, os atores envolvidos na realização do projeto de extensão são: alunos extensionistas dos cursos de CCO e SIN, jovens tutores, mentores voluntários, professor de tecnologia educacional, professores de outras disciplinas e professores do INE/CTC/UFSC. 
Quadro 1 - Atores envolvidos no projeto

\begin{tabular}{|l|l|}
\hline \multicolumn{1}{|c|}{ Ator } & \multicolumn{1}{c|}{ Descrição } \\
\hline Alunos extensionistas de CCO e SIN & $\begin{array}{l}\text { Alunos extensionistas dos cursos de Ciências da Computação } \\
\text { e Sistemas de Informação participantes da iniciativa } \\
\text { Computação na Escola, responsáveis por capacitar e } \\
\text { acompanhar os jovens tutores e conduzir as oficinas de } \\
\text { programação }\end{array}$ \\
\hline Jovens Tutores & $\begin{array}{l}\text { Alunos do 9o ano do Ensino Fundamental, que são } \\
\text { capacitados para o desenvolvimento de aplicativos móveis e } \\
\text { ajudam na aplicação de oficinas de programação para outros } \\
\text { alunos da escola }\end{array}$ \\
\hline Mentores Voluntários & $\begin{array}{l}\text { Profissionais da área de desenvolvimento de software, } \\
\text { funcionários da empresa patrocinadora do projeto, } \\
\text { responsáveis por dar suporte aos jovens tutores e aplicar as } \\
\text { oficinas de programação }\end{array}$ \\
\hline Professor de tecnologia educacional & $\begin{array}{l}\text { Professor responsável pela sala informatizada da escola, } \\
\text { responsável por selecionar os jovens tutores participantes } \\
\text { juntamente com a equipe pedagógica da escola e dar apoio à } \\
\text { execução do projeto }\end{array}$ \\
\hline Professores de outras disciplinas & $\begin{array}{l}\text { Ouros professores da escola indiretamente envolvidos no } \\
\text { projeto, participando das oficinas e apoiando a participação de } \\
\text { alunos }\end{array}$ \\
\hline Computação na Escola & $\begin{array}{l}\text { Professores do INE/CTC/UFSC responsáveis pela } \\
\text { coordenação do projeto e formação dos mentores voluntários, } \\
\text { alunos extensionistas e jovens tutores }\end{array}$ \\
\hline
\end{tabular}

O projeto de extensão foi realizado na Escola Básica Prof. Herondina Medeiros Zeferino, no município de Florianópolis, Santa Catarina, de abril a novembro de 2017. A escola escolhida é a maior escola da rede pública municipal de Florianópolis, com 80 professores e mais de 1.400 alunos divididos em 45 turmas do ensino fundamental, atendendo principalmente pessoas de baixa renda, com 47\% das famílias dos alunos com renda entre 1 e 2 salários mínimos (HERONDINA, 2017).

\section{Abordagem Metodológica}

Algumas abordagens têm sido propostas para realização de extensão universitária para o ensino de programação às escolas, como a abordagem proposta por Scaico et al. (2012), que é adotada como referência para deste projeto. Adicionalmente à abordagem proposta por Scaico et al. (2012), no projeto Jovens Tutores de Programação é utilizado o Peer Tutoring (tutoria pelos pares). Peer Tutoring consiste em colegas de um mesmo grupo social que possuem mais 
conhecimento em determinado assunto atuarem como apoio ao aprendizado dos outros alunos (Topping, 1996). Assim, as seguintes etapas e atividades são realizadas no projeto Jovens Tutores de Programação, conforme apresenta o Quadro 2. A coluna Duração apresentada no Quadro 2 representa os meses de início e fim de cada atividade.

Quadro 2 - Etapas e atividades do projeto

\begin{tabular}{|c|c|c|c|c|}
\hline Etapa & Atividades & Responsável & \multicolumn{2}{|c|}{ Duração } \\
\hline \multirow{2}{*}{$\begin{array}{l}\text { Etapa 1: Preparação da } \\
\text { unidade instrucional e } \\
\text { adaptação das ferramentas } \\
\text { computacionais }\end{array}$} & $\begin{array}{l}\text { Atividade 1.1: Preparar as unidades } \\
\text { instrucionais }\end{array}$ & $\begin{array}{l}\text { Alunos Extensionistas } \\
\text { de CCO e SIN }\end{array}$ & 1 & 1 \\
\hline & $\begin{array}{l}\text { Atividade 1.2: Adaptar as ferramentas } \\
\text { computacionais }\end{array}$ & $\begin{array}{l}\text { Alunos Extensionistas } \\
\text { de CCO e SIN }\end{array}$ & 2 & 6 \\
\hline \multirow{6}{*}{$\begin{array}{l}\text { Etapa 2: Iniciação do } \\
\text { projeto de extensão e } \\
\text { Capacitação geral para } \\
\text { Voluntários e Jovens } \\
\text { Tutores }\end{array}$} & $\begin{array}{l}\text { Atividade 2.1: Tramitar e aprovar o } \\
\text { projeto junto à secretaria municipal de } \\
\text { educação da Prefeitura Municipal de } \\
\text { Florianópolis }\end{array}$ & $\begin{array}{l}\text { Coordenação } \\
\text { Computação na Escola }\end{array}$ & 1 & 2 \\
\hline & $\begin{array}{l}\text { Atividade 2.2: Divulgar o projeto na } \\
\text { escola e nas empresas }\end{array}$ & $\begin{array}{l}\text { Coordenação } \\
\text { Computação na Escola }\end{array}$ & 2 & 2 \\
\hline & $\begin{array}{l}\text { Atividade 2.3: Selecionar Jovens Tutores e } \\
\text { Mentores Voluntários }\end{array}$ & $\begin{array}{l}\text { Coordenação } \\
\text { Computação na Escola } \\
\text { e Professor de } \\
\text { tecnologia educacional }\end{array}$ & 2 & 2 \\
\hline & $\begin{array}{l}\text { Atividade 2.4: Realizar visita dos } \\
\text { candidatos a Jovens Tutores à empresa de } \\
\text { TI patrocinadora }\end{array}$ & \multirow{3}{*}{$\begin{array}{l}\text { Coordenação } \\
\text { Computação na Escola, } \\
\text { Alunos Extensionistas } \\
\text { de CCO e SIN e } \\
\text { Professor de tecnologia } \\
\text { educacional }\end{array}$} & 3 & 3 \\
\hline & $\begin{array}{l}\text { Atividade 2.5: Planejar e realizar } \\
\text { formações para Jovens Tutores e } \\
\text { Mentores Voluntários }\end{array}$ & & 4 & 7 \\
\hline & Atividade 2.6: Avaliar as formações & & 7 & 7 \\
\hline \multirow{2}{*}{$\begin{array}{l}\text { Etapa 3: Formação dos } \\
\text { Jovens Tutores }\end{array}$} & $\begin{array}{l}\text { Atividade } 3.1 \text { Treinar os Jovens Tutores } \\
\text { para o desenvolvimento dos seus próprios } \\
\text { aplicativos }\end{array}$ & \multirow{2}{*}{$\begin{array}{l}\text { Mentores Voluntários e } \\
\text { Alunos Extensionistas } \\
\text { de CCO e SIN }\end{array}$} & 3 & 7 \\
\hline & $\begin{array}{l}\text { Atividade } 3.2 \text { Acompanhar e auxiliar os } \\
\text { Jovens Tutores no desenvolvimento dos } \\
\text { seus próprios aplicativos }\end{array}$ & & 3 & 7 \\
\hline \multirow{4}{*}{$\begin{array}{l}\text { Etapa 4: Realização de } \\
\text { Oficinas de Programação de } \\
\text { Aplicativos Móveis }\end{array}$} & $\begin{array}{l}\text { Atividade 4.1: Divulgar as oficinas de } \\
\text { desenvolvimento de Apps na escola }\end{array}$ & $\begin{array}{l}\text { Jovens Tutores e } \\
\text { Professor de tecnologia } \\
\text { educacional }\end{array}$ & 1 & 2 \\
\hline & $\begin{array}{l}\text { Atividade 4.2: Planejar as oficinas de } \\
\text { desenvolvimento de Apps }\end{array}$ & $\begin{array}{l}\text { Coordenação } \\
\text { Computação na Escola }\end{array}$ & 3 & 3 \\
\hline & $\begin{array}{l}\text { Atividade 4.3: Realizar as oficinas de } \\
\text { desenvolvimento de Apps }\end{array}$ & $\begin{array}{l}\text { Jovens Tutores, } \\
\text { Mentores Voluntários e } \\
\text { Alunos Extensionistas } \\
\text { de CCO e SIN }\end{array}$ & 4 & 7 \\
\hline & Atividade 4.4: Avaliar as oficinas & $\begin{array}{l}\text { Coordenação } \\
\text { Computação na Escola }\end{array}$ & 7 & 7 \\
\hline $\begin{array}{l}\text { Etapa 5: Documentação, } \\
\text { divulgação dos resultados e }\end{array}$ & $\begin{array}{l}\text { Atividade 5.1: Documentar os resultados } \\
\text { em um artigo científico }\end{array}$ & $\begin{array}{l}\text { Jovens Tutores, } \\
\text { Mentores Voluntários, }\end{array}$ & 6 & 7 \\
\hline
\end{tabular}


Jovens tutores de programação: um relato de experiência

\begin{tabular}{|c|c|c|c|c|}
\hline \multirow[t]{2}{*}{ Encerramento do projeto } & $\begin{array}{l}\text { Atividade 5.2: Preparar um website para } \\
\text { distribuição do material instrucional }\end{array}$ & \multirow{2}{*}{$\begin{array}{l}\text { Alunos Extensionistas } \\
\text { de CCO e SIN e } \\
\text { Professor de tecnologia } \\
\text { educacional }\end{array}$} & 6 & 7 \\
\hline & Atividade 5.3: Encerramento do Projeto & & 8 & 8 \\
\hline
\end{tabular}

\section{RESULTADOS E ANÁLISES}

Nesta seção são apresentados e discutidos os principais resultados de cada uma das etapas do projeto.

\section{Etapa 1: Preparação da unidade instrucional e adaptação das ferramentas computacionais}

Na Etapa 1 as unidades instrucionais necessárias para a formação de jovens tutores de programação e para a formação de mentores voluntários foram preparadas seguindo o modelo ADDIE (Branch, 2010) para o desenvolvimento de unidades instrucionais. Seguindo esse modelo, inicialmente foi realizada pelos alunos extensionistas uma análise de contexto, caracterizando o público-alvo e o ambiente, além de identificar objetivos típicos de aprendizagem e estratégias de instrução para o ensino de programação para jovens tutores.

Durante o design das unidades instrucionais, em relação ao conteúdo, dois aspectos foram contemplados: (i) aspectos técnicos de desenvolvimento de aplicativos móveis utilizando ferramentas apropriadas para a faixa etária dos jovens tutores e (ii) aspectos pedagógicos, éticos e comportamentais referentes ao ensino de computação para crianças, a serem ministrados tanto para os jovens tutores quanto para os mentores voluntários. Extratos das unidades instrucionais elaboradas são apresentados na Ilustração 1. 


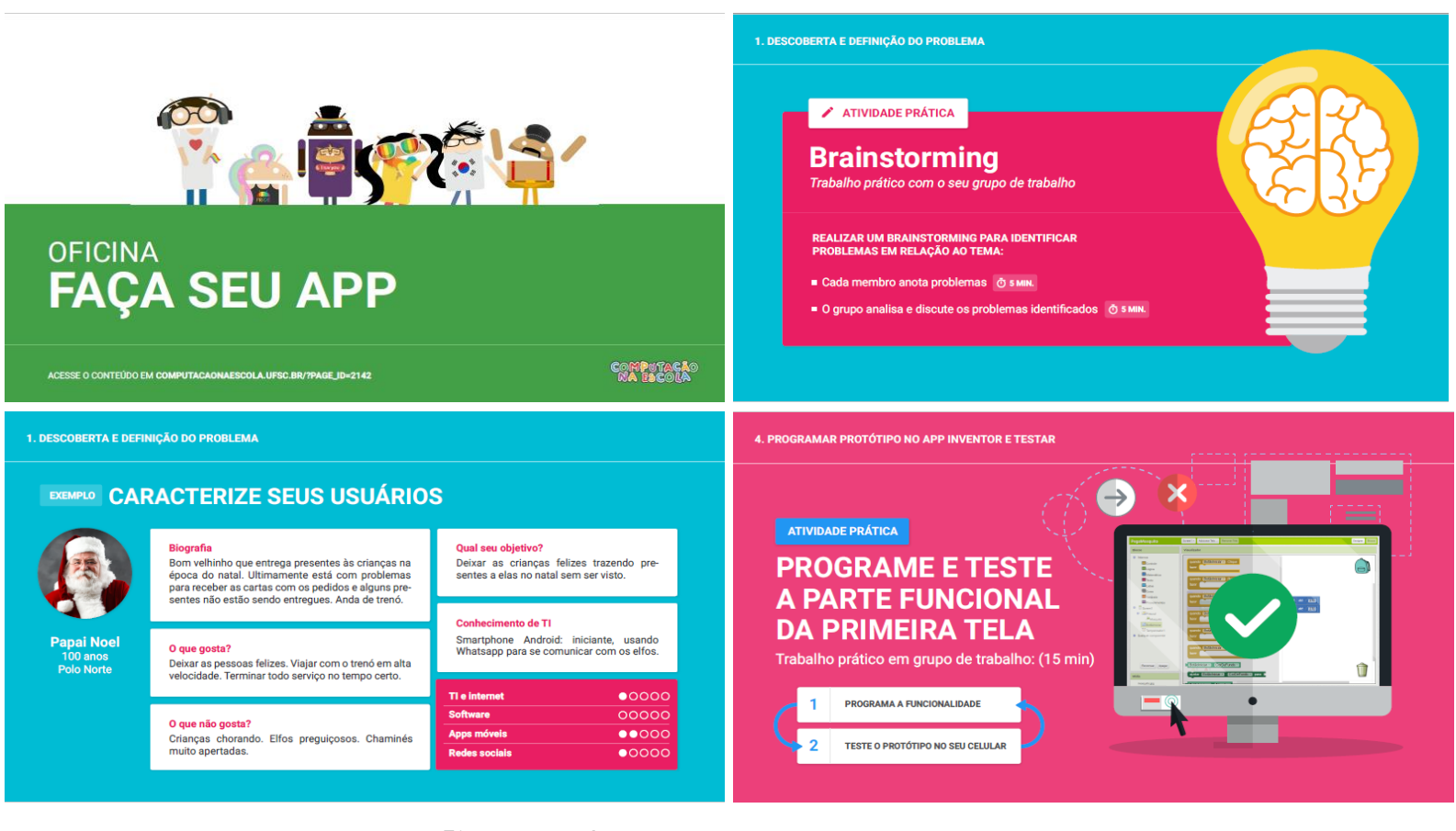

Ilustração 1 - Extrato da Unidade Instrucional. Fonte: Elaboração dos autores.

Ainda nessa etapa, as ferramentas computacionais necessárias para a realização das oficinas na escola foram também preparadas. Inicialmente a estrutura da ferramenta App Inventor (http://ai2.appinventor.mit.edu/) foi estudada em detalhes pelos alunos extensionistas, sendo modeladas soluções computacionais para as oficinas e realizados testes.

\section{Etapa 2: Iniciação do projeto de extensão e Capacitação geral para Voluntários e Jovens Tutores}

Logo no início da Etapa 2, o projeto de extensão foi aprovado junto à Secretaria de Educação da Prefeitura Municipal de Florianópolis. Na sequência foi realizado um evento de divulgação do projeto na Escola Herondina com o objetivo de atrair interesse dos alunos das turmas de $8^{\circ}$ e $9^{\circ}$ anos para serem possíveis jovens tutores. Após esse evento, 25 alunos dos anos finais do Ensino Fundamental da escola indicaram interesse em participar do projeto e, dentre esses, a escola selecionou 3 alunos a partir do interesse dos estudantes na área de tecnologia, da realização de entrevista individual e entrevista com a família.

Todos os 25 alunos interessados realizaram, então, uma visita à empresa patrocinadora do projeto: Involves Tecnologia (http://www.involves.com.br), e lá conheceram um pouco do dia-adia de uma empresa de tecnologia, visitando cada um dos setores e conversando com um representante de cada função típica relacionada à computação. A Ilustração 2 mostra algumas imagens da visita à empresa. 


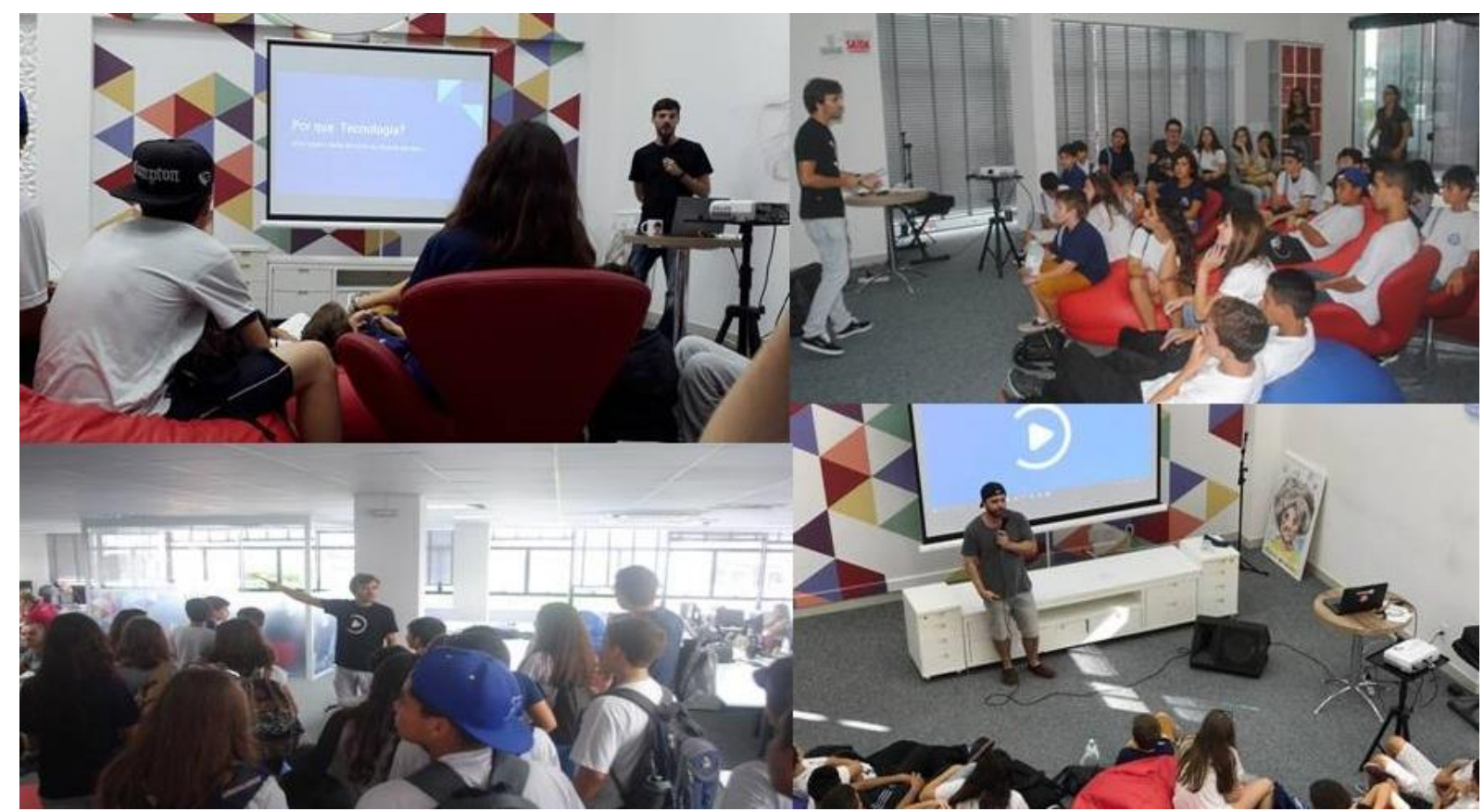

Ilustração 2 - Visita dos Jovens Tutores e alunos à empresa de TI. Fonte: Elaboração dos autores.

Após a visita à empresa, foram realizadas as formações gerais dos jovens tutores e mentores voluntários (Ilustração 3). A capacitação foi ministrada por professores e alunos extensionistas de Sistemas de Informação e Ciências da Computação membros da Iniciativa Computação na Escola. A Ilustração 3 mostra uma imagem da reportagem realizada pela TV UFSC sobre a formação para mentores e jovens tutores, realizado no INE/CTC/UFSC1.

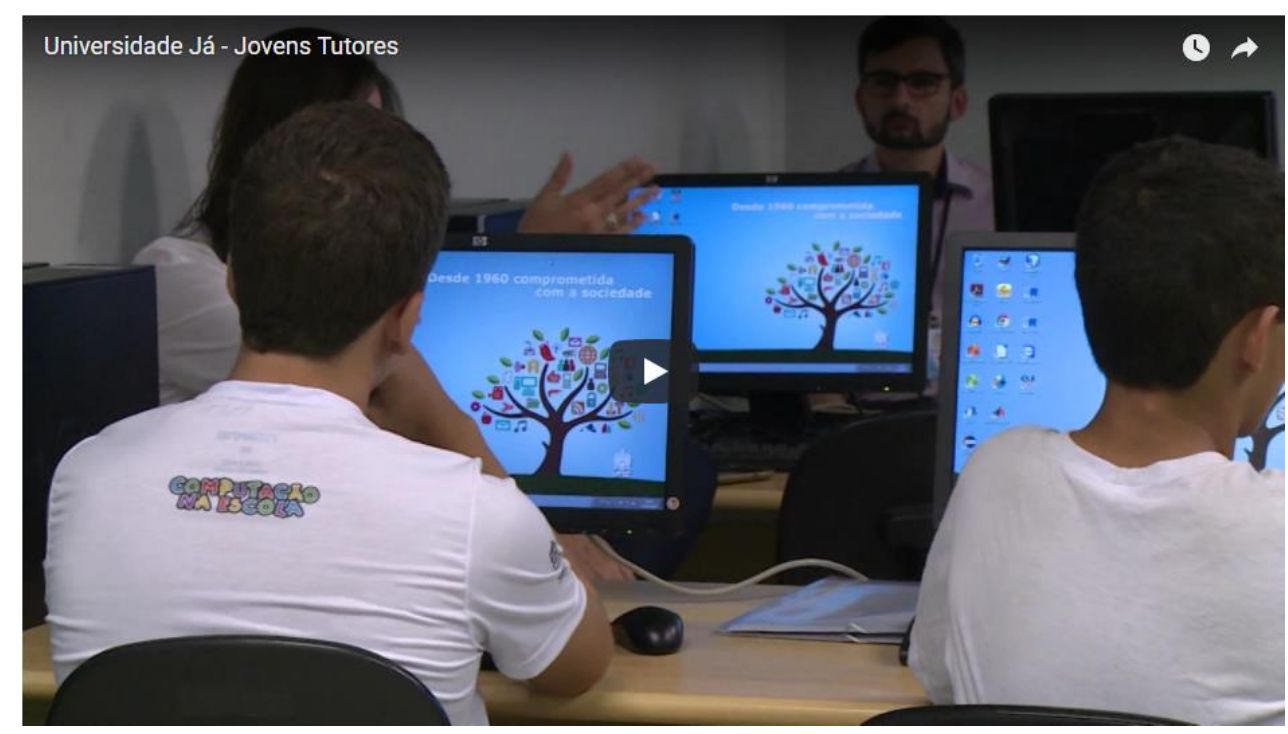

Ilustração 3 - Reportagem produzida pela TV UFSC sobre a capacitação dos Tutores e Mentores Fonte: TV UFSC.

\footnotetext{
${ }^{1}$ https://www.youtube.com/watch?v=INYLjf4QkZ8
} 
Jovens tutores de programação: um relato de experiência

\section{Etapa 3: Formação dos Jovens Tutores}

Nessa etapa, durante quatro meses, os jovens tutores tiveram encontros semanais na escola para formação aprofundada em desenvolvimento de aplicativos móveis com App Inventor (vide ). Essa formação mais longa de desenvolvimento de aplicativos móveis teve como objetivo ampliar os conhecimentos dos jovens tutores, capacitando-os para que possam ser multiplicadores do conhecimento dentro da escola e também possibilitando que os jovens tutores possam desenvolver seus próprios aplicativos móveis.
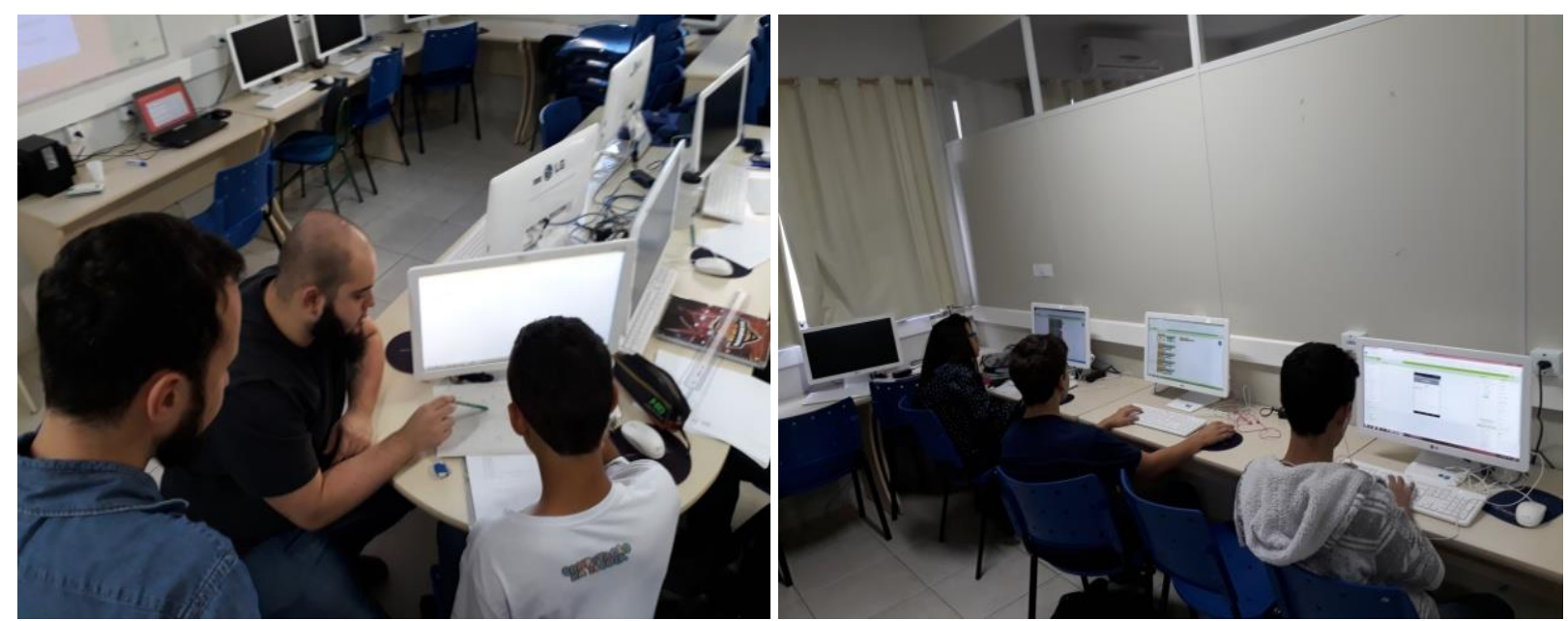

Ilustração 4 - Formação e acompanhamento dos jovens tutores no desenvolvimento dos seus Apps Fonte: Elaboração dos autores.

Assim, cada um dos jovens tutores recebeu capacitação e acompanhamento para aprender a desenvolver seu próprio aplicativo, seguindo conceitos de Design Tbinking, design de interface/UX e programação.

Os jovens tutores foram conduzidos a buscar resolver problemas da escola e da comunidade local por meio do desenvolvimento dos seus aplicativos. Os aplicativos foram concebidos, modelados e desenvolvidos e, como resultado do projeto, ficam prontos para sua utilização inicial. Além dos jovens tutores, também alguns professores se sentiram motivados a participar e se envolveram na realização dessas formações. Durante esse período, foram desenvolvidos pelos alunos e por um dos professores da escola os seguintes aplicativos (vide 
Jovens tutores de programação: um relato de experiência
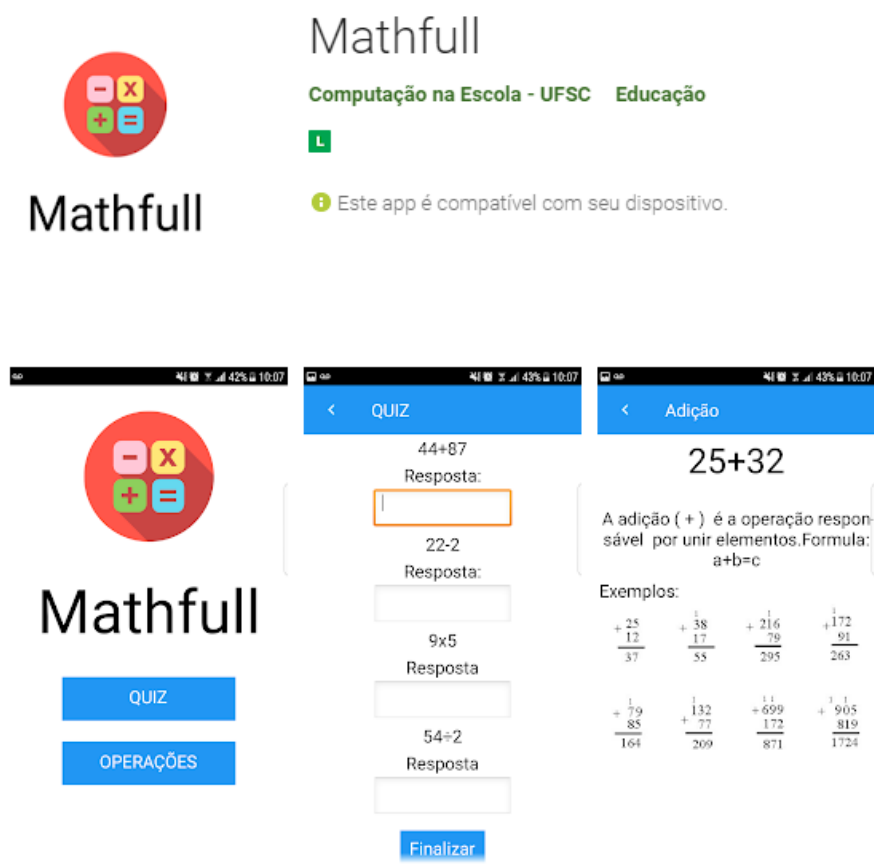

Exemplos:

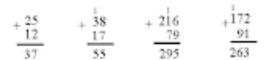

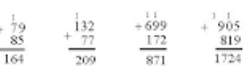

Mathfull é um aplicativo desenvolvido com objetivos educacionais que contém um quiz com as

Ilustração 5):

1. Aplicativo Mathfull: Quiz contendo as quatro operações matemáticas, desenvolvido por: Richard de Souza Bercheli (Aluno do 9. ano). Download: https://goo.gl/mZ9VUg

2. Aplicativo Info Herondina: Aplicativo com o objetivo de facilitar a comunicação entre familiares e profissionais da escola, desenvolvido por: Nicolas Pedroso (Aluno do $9^{\circ}$. ano). Download do APK: https://goo.gl/xPXwYn .

3. Aplicativo Veganizando: Apresenta informações educativas sobre vegetarianos e veganos. Desenvolvido por: Júlia Sena Amaral da Silva (Aluna do $9^{\circ}$. ano). Download: https://goo.gl/qPtVk4.

4. Aplicativo EducPortifólio: Permite o registro diário de anotações de aula pelo professor. Desenvolvido por: Lauriano Warth (Professor de educação física da escola).

Mais informações sobre os aplicativos e download dos códigos-fonte podem ser encontradas no site da iniciativa Computação na Escola: http://www.computacaonaescola.ufsc.br/?p=2387. 
Jovens tutores de programação: um relato de experiência

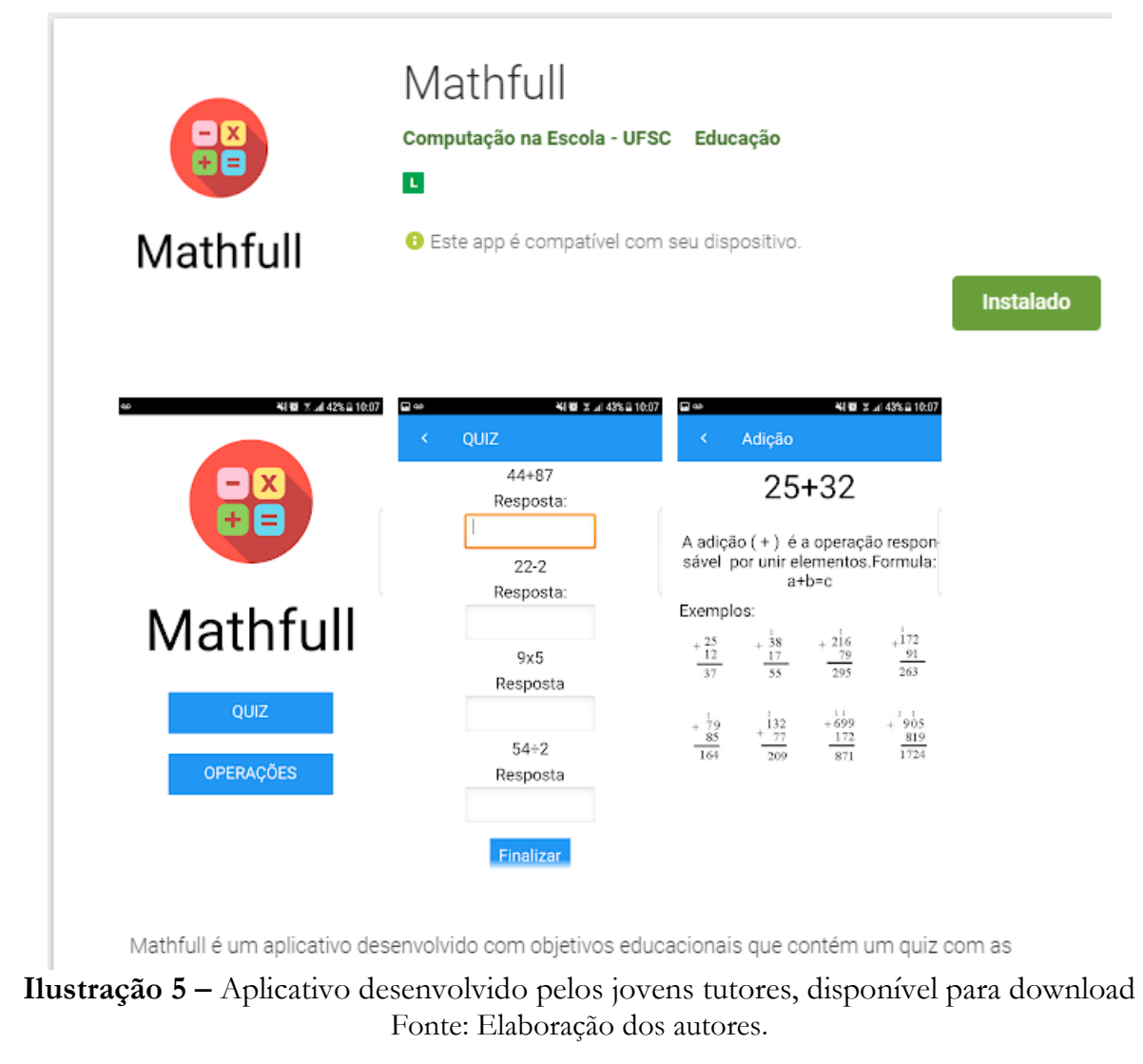

\section{Etapa 4: Realização de Oficinas de Programação de Aplicativos Móveis}

Após o primeiro mês de capacitação dos Jovens Tutores, foram iniciadas as oficinas de desenvolvimento de aplicativos móveis para os demais alunos da escola. As oficinas seguiram a unidade instrucional: Oficina de App Inventor (Jogo Caça Mosquito) ${ }^{2}$. Nessas oficinas de programação os participantes aprendem a programar um jogo que faz um mosquito voar pela tela do celular e o jogador deve tentar matá-lo no tempo permitido.

Ao todo foram planejadas e realizadas três oficinas de programação, nos meses de maio a agosto de 2017. Participaram dessas oficinas os três jovens tutores, seis mentores voluntários, três professores, quatro alunos extensionistas e cinquenta alunos da escola, com idades entre oito e quatorze anos. A Ilustração 6 mostra algumas imagens das oficinas realizadas.

${ }^{2} \mathrm{http}: / /$ www.computacaonaescola.ufsc.br/?page_id=1474 
Jovens tutores de programação: um relato de experiência

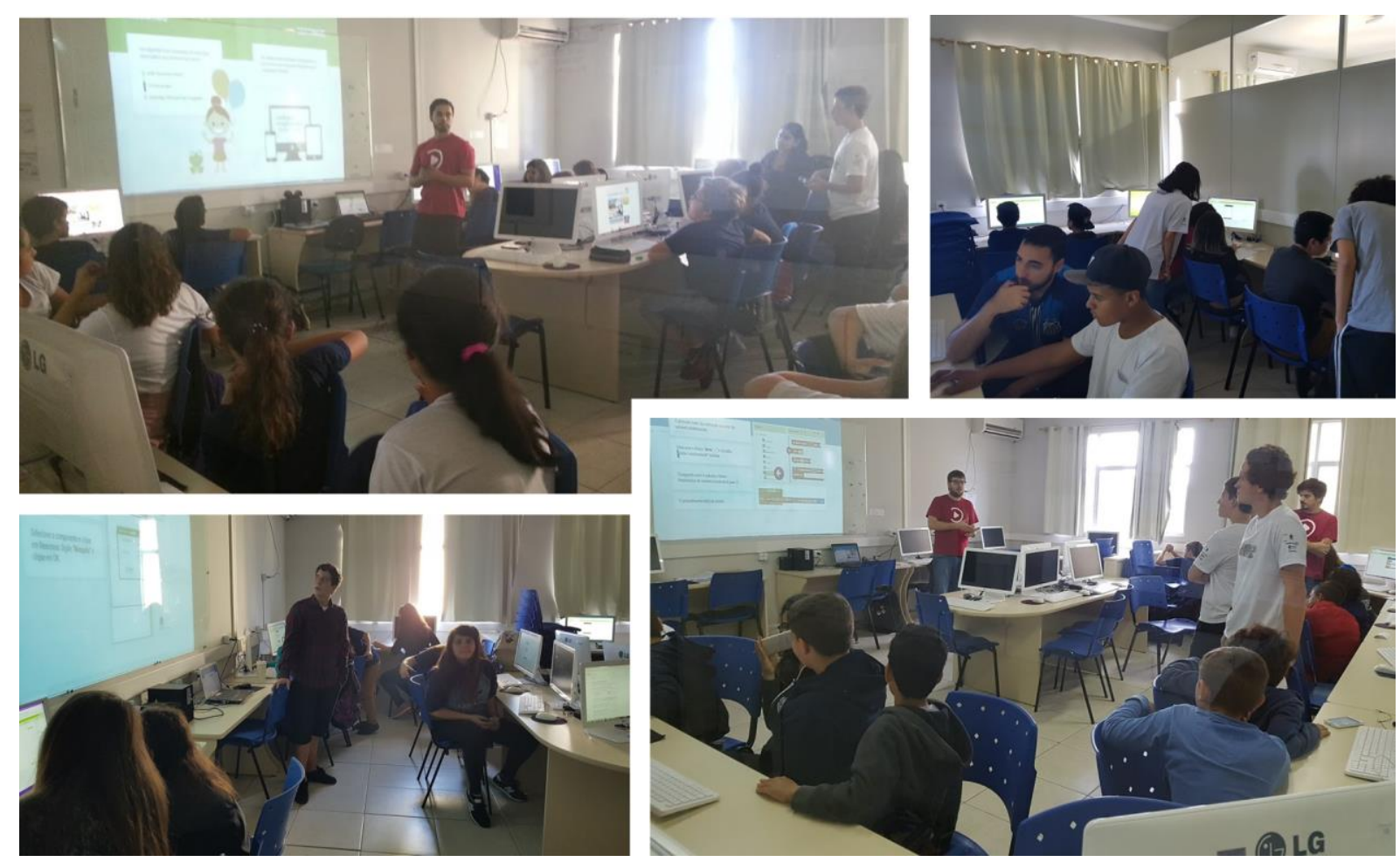

Ilustração 6 - Oficinas de desenvolvimento de Apps para alunos no Ensino Fundamental Fonte: Elaboração dos autores.

Uma reportagem produzida pela RIC $\mathrm{TV}^{3}$ apresenta detalhes sobre as oficinas realizadas na escola (vide Ilustração 7).

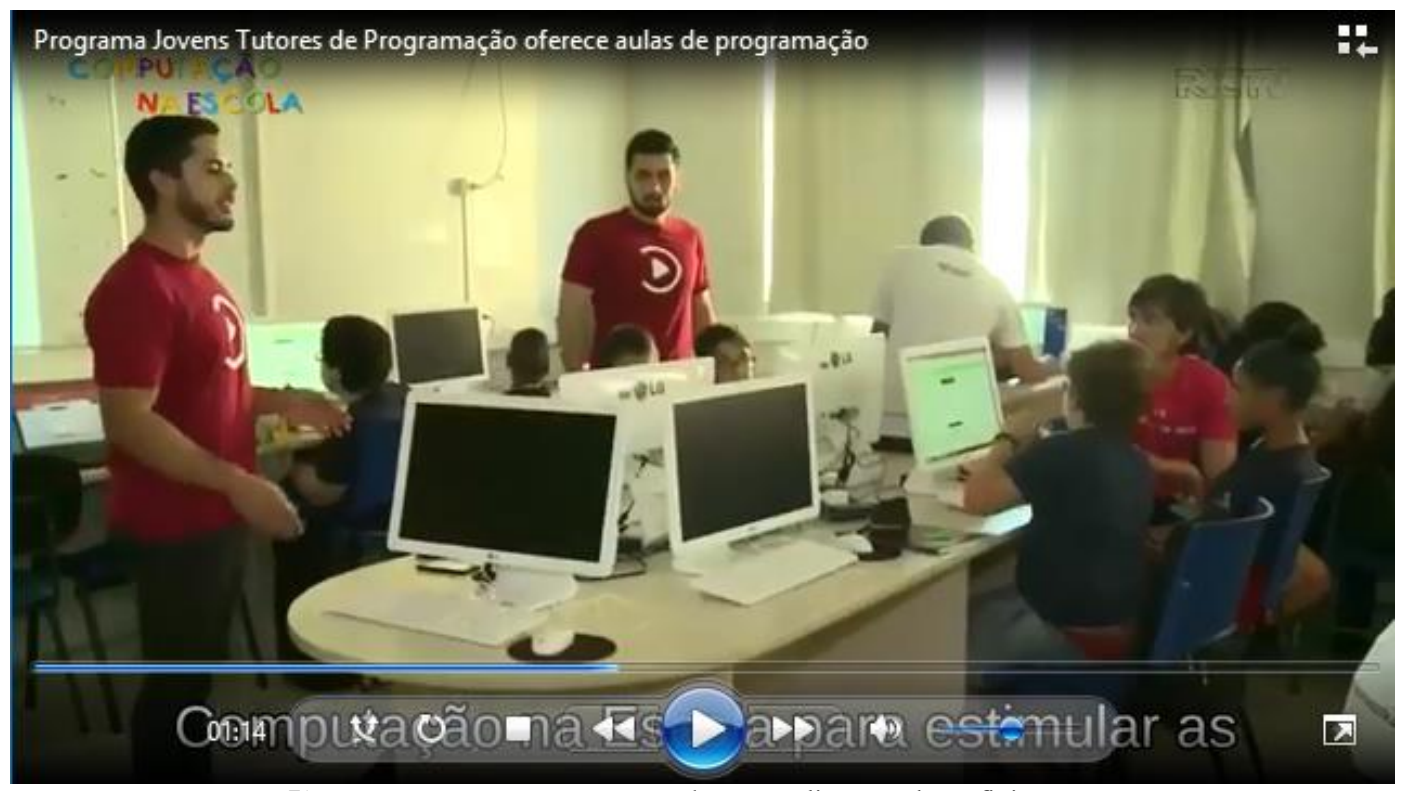

Ilustração 7 - Reportagem sobre a realização das oficinas Fonte: RIC TV.

${ }^{3}$ https://www.youtube.com/watch?v=INYLjf4QkZ8 
Jovens tutores de programação: um relato de experiência

\section{Etapa 5: Documentação, divulgação dos resultados e Encerramento do projeto}

$\mathrm{Na}$ última fase do projeto, os jovens tutores, o professor de tecnologia educacional, alguns professores da escola e professores do INE/CTC/UFSC realizaram evento na sede da empresa patrocinadora para apresentar os principais resultados alcançados com o projeto a todos os envolvidos. Nesse evento, cada um dos jovens tutores apresentou o seu aplicativo desenvolvido, e os aspectos mais relevantes da sua participação no projeto (Ilustração 8).
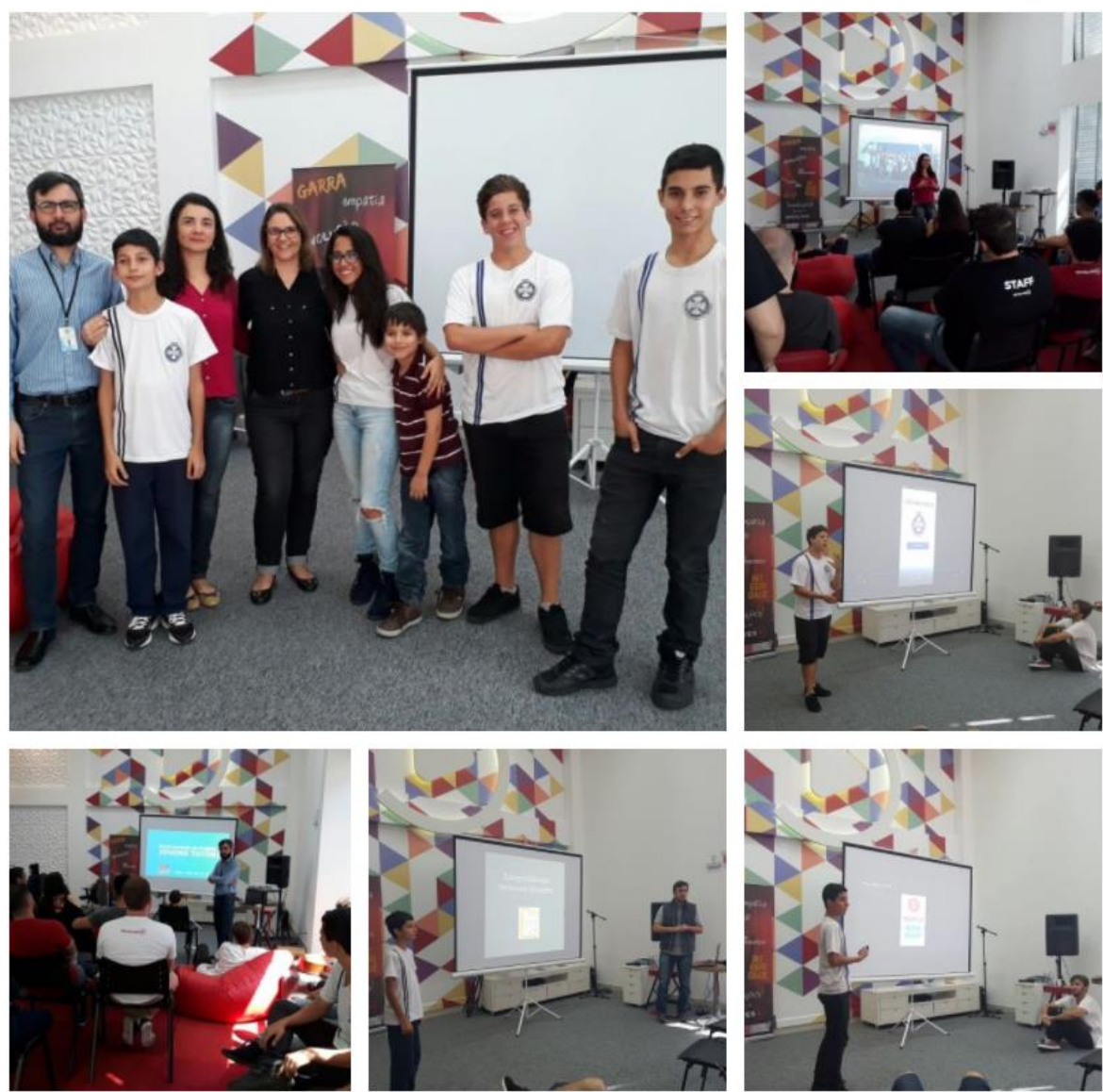

Ilustração 8 - Evento de Encerramento do Projeto Fonte: Elaboração dos autores.

O Quadro 3 destaca os principais resultados obtidos com a realização do projeto, que foram apresentados no evento. 
Quadro 3 - Resumo dos principais resultados do projeto

\begin{tabular}{|l|l|}
\hline Evento & Resultado \\
\hline Capacitação de Jovens Tutores & $\begin{array}{l}\text { Três alunos do } 9^{\circ} \text { ano do ensino treinados no desenvolvimento de aplicativos } \\
\text { móveis durante quatro meses }\end{array}$ \\
\hline $\begin{array}{l}\text { Capacitação de Mentores } \\
\text { Voluntários }\end{array}$ & $\begin{array}{l}\text { Seis profissionais de TI treinados para atuarem como voluntários no ensino de } \\
\text { programação de aplicativos móveis para crianças }\end{array}$ \\
\hline $\begin{array}{l}\text { Oficinas de programação de } \\
\text { aplicativos móveis }\end{array}$ & $\begin{array}{l}\text { Cinquenta alunos do Ensino Fundamental participaram de três oficinas de } \\
\text { programação de aplicativos móveis oferecidas no contraturno escolar }\end{array}$ \\
\hline $\begin{array}{l}\text { Divulgação científica e prêmios } \\
\text { recebidos }\end{array}$ & $\begin{array}{l}\text { Premiação de Destaque na Feira Municipal de Ciências, Matemática e Geografia } \\
\text { de Florianópolis }\end{array}$ \\
\cline { 2 - 2 } & Premiação de Destaque na IV Feira Regional de Matemática \\
\cline { 2 - 2 } & $\begin{array}{l}\text { Premiação de Destaque na Categoria III da Feira Brasileira de Iniciação Científica } \\
2017\end{array}$ \\
\cline { 2 - 2 } & Premiação de $1^{\circ}$ lugar Categoria II da Feira Brasileira de Iniciação Científica 2017 \\
\cline { 2 - 2 } & $\begin{array}{l}\text { Premiação de Excelência em Iniciação Científica da Feira Brasileira de Iniciação } \\
\text { Científica 2017 }\end{array}$ \\
\hline
\end{tabular}

Dentre os principais resultados do projeto, destaca-se a formação dos três jovens tutores, que conseguiram, ao final do projeto, desenvolver seus próprios aplicativos móveis, atendendo a problemas locais identificados pela comunidade escolar. Além da formação técnica, os jovens tutores também relataram ao final do projeto, o desenvolvimento de outras habilidades não relacionadas à programação, tais como: comunicação, trabalho em grupo, persistência e resolução de problemas.

Os mentores voluntários e alunos extensionistas demonstraram satisfação na participação no projeto. Além disso, também relataram desenvolvimento de habilidades de ensino, comunicação e trabalho em grupo em decorrência da participação no projeto.

Da mesma forma, com a participação dos jovens tutores, mentores voluntários e alunos extensionistas, foram capacitados cinquenta alunos que participaram das oficinas, sendo que a maioria nunca havia tido contato com programação. Ao final das oficinas, a maioria dos participantes relatou que gostou do conteúdo apresentado, que aprendeu noções de programação de aplicativos para celular e se mostrou motivado a continuar aprendendo.

\section{CONSIDERAÇÕES FINAIS}

Este artigo apresenta o projeto de extensão universitária Jovens Tutores de Programação, que visa capacitar jovens dos últimos anos do ensino fundamental para a aplicação e ensino de programação de aplicativos móveis, envolvendo profissionais da indústria de software e alunos extensionistas, ao mesmo tempo que se ensina o conhecimento computacional e programação para outras crianças em uma escola pública municipal de Florianópolis. O projeto foi realizado na 
Jovens tutores de programação: um relato de experiência

escola pública municipal Herondina Medeiros Zeferino, gerando diversos resultados positivos. Durante o projeto, três jovens foram capacitados para desenvolverem seus próprios aplicativos e para serem tutores no ensino de outros estudantes da mesma escola. Nas oficinas de programação de aplicativos, realizadas em contraturno escolar, cinquenta estudantes aprenderam conceitos fundamentais de programação e de desenvolvimento de aplicativos móveis com o apoio dos jovens tutores.

Trabalhos futuros envolvem a realização de novas edições do projeto em outras escolas e a utilização de outras ferramentas adicionais de apoio ao ensino de computação, como a ferramenta CodeMaster (http://apps.computacaonaescola.ufsc.br:8080) desenvolvida pela Iniciativa Computação na Escola e que automatizada a avaliação de diversos aspectos do pensamento computacional, podendo facilitar a realização de projetos deste tipo.

\section{AGRADECIMENTOS}

Os autores agradecem à empresa patrocinadora do projeto: Involves Tecnologia e aos profissionais de desenvolvimento de software que participaram como mentores voluntários.

Este trabalho foi parcialmente financiado pelo CNPq (Conselho Nacional de Desenvolvimento Científico e Tecnológico), uma entidade do governo brasileiro focado no desenvolvimento científico e tecnológico e pelo Programa de Bolsas de Extensão PROBOLSAS da Universidade Federal de Santa Catarina.

\section{REFERÊNCIAS}

BRANCH, R. M. Instructional design: The ADDIE approach. Springer Science \& Business Media, 2010.

CASTRO, L. M. C. A universidade, a extensão universitária e a produção de conhecimentos emancipadores. Reunião Anual da ANPED, v. 27, p. 1-16, 2004.

CSTA - Computer Science Teachers Association. K-12 Computer Science Framework. Disponível em: <http://www.k12cs.org>, 2016.

IBGE. Acesso à Internet e à televisão e posse de telefone móvel celular para uso pessoal. Pesquisa Nacional por Amostra de Domicílios Contínua 2016. IBGE, 2016.

INCOD/INE/UFSC. Computação na Escola. Disponível em: <http://www.computacaonaescola.ufsc.br> Acessado em maio, 2018.

LYE, Sze Yee; KOH, Joyce Hwee Ling. Review on teaching and learning of computational thinking through programming: What is next for K-12?. Computers in Human Behavior, v. 41, p. 51-61, 2014. 
Jovens tutores de programação: um relato de experiência

NATIONAL RESEARCH COUNCIL. Report of a workshop on the pedagogical aspects of computational thinking. National Academies Press, 2011.

NUNES, A. L. P. F.; SILVA, M. B. C. A extensão universitária no ensino superior e a sociedade. Mal-Estar e Sociedade, v. 4, n. 7, p. 119-133, 2011.

HERONDINA Medeiros Zeferino, PPP - Projeto Político Pedagógico. Disponível em: $<$ http://www.escolaherondina.net>. Acessado em maio, 2018.

RODRIGUES, A. L. L.; COSTA, C. L. N. A., PRATA, M. S.; BATALHA, T. B. S., NETO, I. F. P. Contribuições da extensão universitária na sociedade. Caderno de Graduação-Ciências Humanas e Sociais-UNIT, v. 1, n. 2, p. 141-148, 2013.

SCAICO, P. D.; CORLETT, E. F.; L. F. P.; RAPOSO, E. H. S. R.; ALENCAR, Y. Relato da Utilização de uma Metodologia de Trabalho para o Ensino de Ciência da Computação no Ensino Médio. Anais do XVIII Workshop de Informática na Escola, Rio de Janeiro. 2012.

TECHNOVATION CHALLENGE BRASIL. Disponível em: $<$ http://www.technovationbrasil.org/>. Acessado em maio, 2018.

TOPPING, K. J. The effectiveness of peer tutoring in further and higher education: A typology and review of the literature. Higher education, v. 32, n. 3, p. 321-345, 1996.

WILSON, C.; SUDOL, L. A.; STEPHENSON, C.; STEHLIK, M. Running on empty: The failure to teach K-12 computer science in the digital age. Association for Computing Machinery, 2010.

Recebido em: 25/05/2018

Aceito em: 06/07/2018 